\title{
Hepatic artery aneurysm: incidental diagnosis with abdominal ultrasonography and treatment by coil embolization
}

\author{
Aneurisma de artéria hepática: diagnóstico incidental com ultrassonografia do abdome e \\ tratamento por embolização com molas \\ Luis Jesuino de Oliveira Andrade ${ }^{1,2}$, Antonio Carlos Botelho da Silva², Larissa Santos França², \\ Luciana Santos França², José Rebouças de Souza²
}

\begin{abstract}
Hepatic artery aneurysm (HAA) was first reported at autopsy in 1809, represents one fifth of visceral aneurysms and the mortality from spontaneous rupture is high in most of cases. We are reporting a case of an asymptomatic 48-year-old woman with an extrahepatic HAA, diagnosed initially and incidentally with abdominal ultrasonography, confirmed by a three-dimensional contrast-enhanced magnetic resonance imaging and angiography. Endovascular treatment was considered feasible and was successfully treated with coil embolization.

Keywords: hepatic artery; aneurysm; vascular diseases; embolization, therapeutic.

\section{Resumo}

Aneurisma da artéria hepática (AAH) foi relatado pela primeira vez através de autópsia em 1809, representa um quinto dos aneurismas viscerais, e a mortalidade por ruptura espontânea é alta na maioria dos casos. Relatamos o caso de uma mulher de 48 anos de idade com um AAH extra-hepático assintomático, diagnosticado inicialmente, e incidentalmente, com ultrassonografia abdominal e confirmado através de angiorressonância tridimensional e angiografia contrastada. O tratamento endovascular foi considerado viável, sendo tratada com sucesso através de embolização com molas.
\end{abstract}

Palavras-chave: artéria hepática; aneurisma; doenças vasculares; embolização terapêutica.

\section{Introduction}

The celiac artery has three branches: the left gastric, splenic and common hepatic arteries. The common hepatic artery divides into the gastroduodenal and proper hepatic arteries. The common hepatic artery usually divides into the right and left hepatic arteries, which supply the liver.

Hepatic artery aneurysm (HAA) was first reported at autopsy in 1809, comprises one fifth of aneurysms affecting splanchnic vessels and your rupture are potentially life threatening in most if not all cases ${ }^{1,2}$. Almost 50\% of HAA are pseudoaneurysms. True aneurysms occur four times more frequently in the extrahepatic arteries, usually involve the common hepatic artery and traditionally represent $20 \%$ of all visceral aneurysms and occur more frequently in men than in women ${ }^{3}$.
The HAA are associated mainly with arteriosclerosis and acquired medial degeneration. Other causes include mycotic aneurysms, trauma, polyarteritis nodosa, pancreatitis, liver transplantation, neurofibromatosis, Wegener granulomatosis, and tuberculosis ${ }^{4}$. Currently HAA is the most frequently visceral artery aneurysm and is probably related to the increasing use of percutaneous diagnostic and therapeutic procedures 5 .

The widespread use of ultrasonography (US) and computed tomography (CT) has led to increased detection of asymptomatic aneurysms. The definitive diagnosis of HAA is made with contrast angiography, but it also can be made with high-quality $\mathrm{CT}$ and magnetic resonance imaging (MRI).

The treatment of HAA varies, can be treated surgically, and more recently, endovascular techniques have become

Study carried out at the Santa Casa de Itabuna - Itabuna (BA), Brazil.

${ }^{1}$ Faculdade de Medicina da Universidade Estadual de Santa Cruz - Ilhéus (BA), Brasil.

${ }^{2}$ Santa Casa de Itabuna - Itabuna (BA), Brasil.

Conflict of interest: nothing to declare.

Submitted on: 08.06.11. Accepted on: 01.03.12.

J Vasc Bras. 2012;11(3):232-235. 
more frequent ${ }^{6}$. The treatment depends on the location, type and size of the aneurysm, and the medical condition of the patient ${ }^{7}$. Currently HAA has been successfully treated by endovascular embolization.

We are reporting a patient asymptomatic with an extrahepatic HAA, diagnosed incidentally on abdominal US and was successfully treated with coil embolization.

\section{Case report}

A 48-year-old woman was admitted with an HAA. The asymptomatic aneurysm was found incidentally as a result of an abdominal US in hers routine outpatient checkups. Gray scale abdominal US revealed one well-defined, rounded cystic masses measuring $4.5 \mathrm{~cm}$ in diameter in the region of the hepatic hilum, and Doppler US was performed to evaluate the vascularity associated with the lesions revealed pulsatile flow within the lesions with a vascular origin (Figure 1). The findings suggested HAA, followed by a three-dimensional contrast-enhanced MRI angiography (Figure 2) and contrast angiography which confirmed the diagnosis (Figure 3). The personal clinical history reported that open cholecystectomy was carried out 20 years ago. Endovascular treatment was considered feasible and it was decided to perform the technique of coil embolization. Angiography of celiac trunk and hepatic artery were performed from a right common femoral artery approach, using a 6F Cobra diagnostic catheter (Terumo Europe N.V. Leuven, Belgium) and Ultravist 370 (Bayer HealthCare Pharmaceutical Inc. USA) contrast agent. The tip of this catheter was positioned in neck of the aneurysm to the remodeling (EV3 Hiperglide $6 \mathrm{~mm}$ ), and another tip was positioned within the aneurysm sac. The balloon was inflated to $4 \mathrm{~mm}$ away from the aneurysm and then through the microcatheter, were placed the aneurysmal sac microcoil (GDC Boston Scientific, Natick, MA, USA). A post coiling and post-angioplasty angiogram showed complete occlusion of the aneurysm, with the coil occluding the aneurysm. This was also confirmed by a hepatic artery angiogram (Figure 4). After the procedure, the patient had

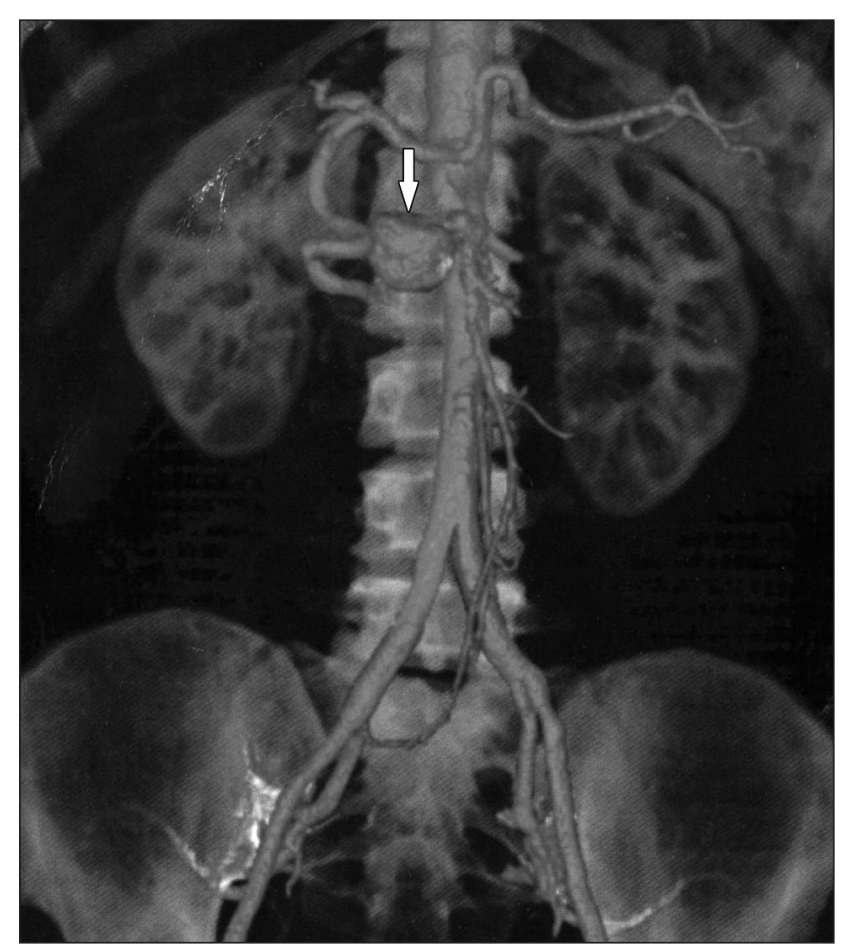

Figure 2. Magnetic Resonance Imaging angiography: three-dimensional volume-rendered image clearly depicts aneurysm.
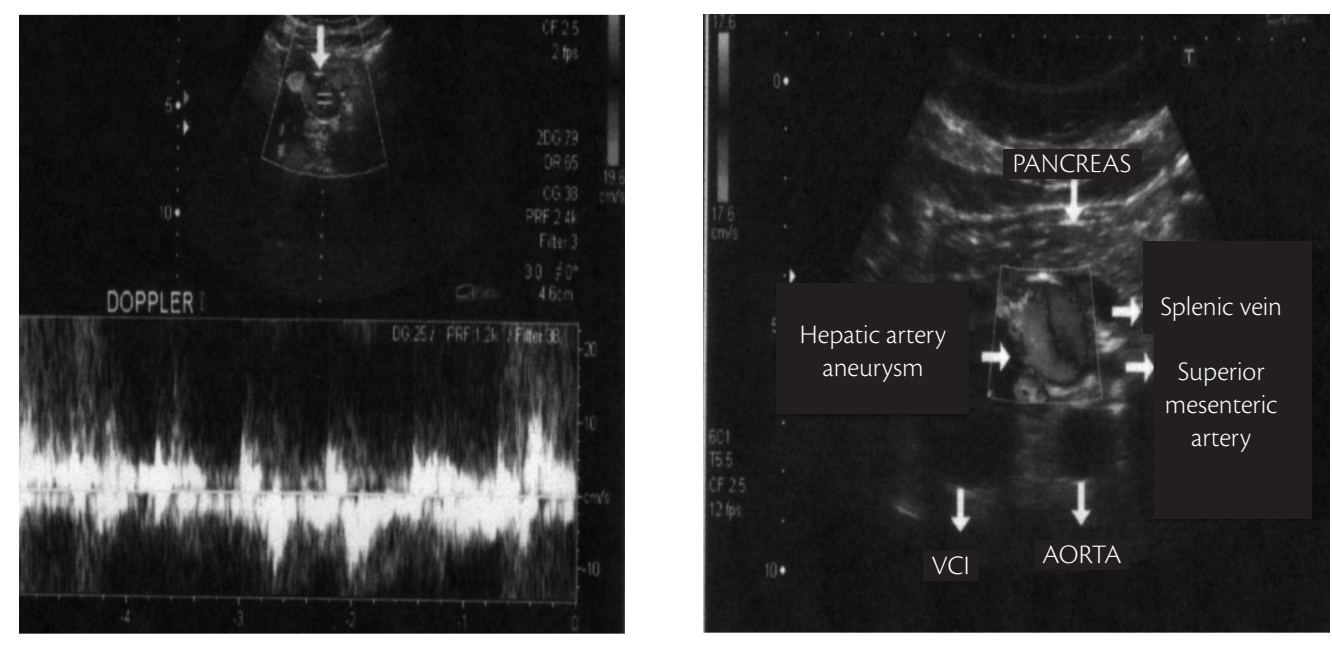

Figure 1. Doppler ultrasonography shows hepatic artery aneurysm. 


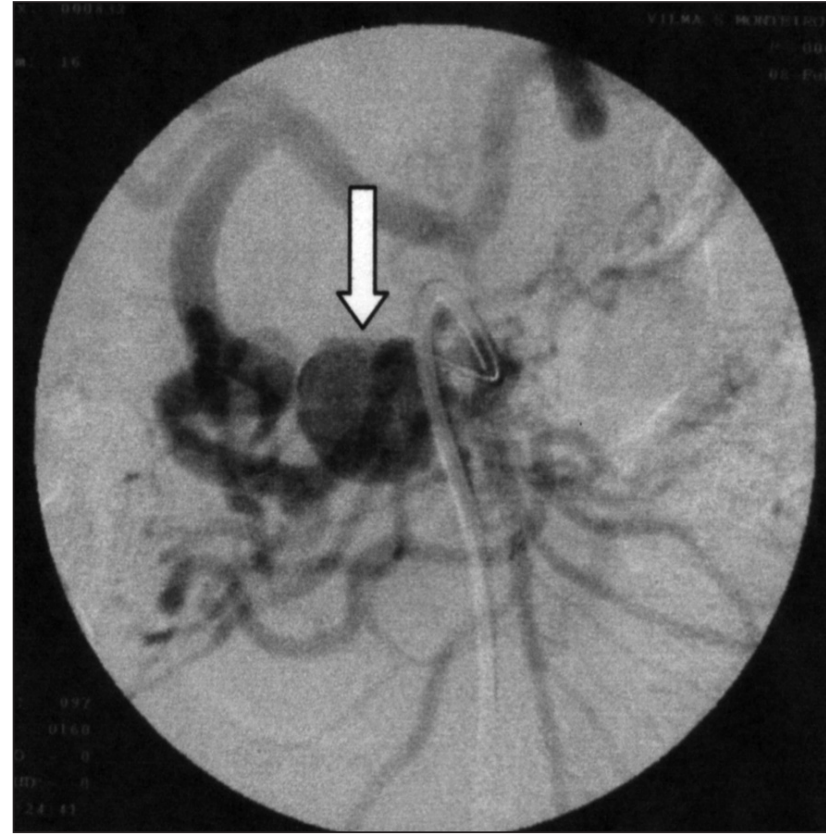

Figure 3. Celiac arteriogram shows the common hepatic artery aneurysm (arrow).

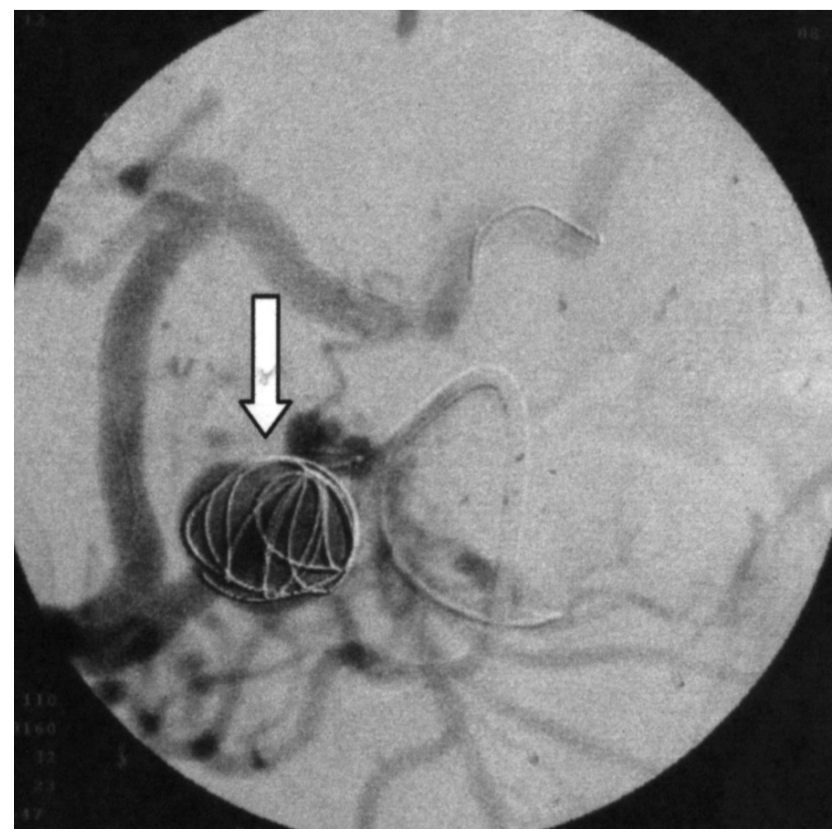

Figure 4. Common hepatic artery aneurysm after the coiling procedure (arrow).

mild abdominal pain. Two weeks after the embolization, the patient was completely without symptoms. Evaluation with MRI angiography carried out three months later confirmed the sealing of the aneurysm and the patency of the hepatic artery. The patient made a good recovery and was well at hers routine outpatient check-ups.

\section{Discussion}

The HAA represents approximately $20 \%$ of all splanchnic aneurysms and is not initially diagnosed in many cases because the most patients with HAA are asymptomatic until rupture $^{8}$. The clinical diagnosis of HAA may be suggested by the classical triad of right upper quadrant pain, gastrointestinal hemorrhage and jaundice which was described as early as 1892 is only present in up to $33 \%$ of cases $^{5,9}$ and more than $50 \%$ of patients present with right upper quadrant abdominal pain that radiates to the back. Physical examination is usually normal and combining the appropriate imaging techniques makes the definitive diagnosis of HAA.

In our case, the patient was asymptomatic and was diagnosed incidentally with abdominal US in hers routine outpatient check-ups. US is an excellent noninvasive method in the evaluation of the liver and porta hepatis for the presence of HAA and customary use of US has led to increased diagnosis of asymptomatic aneurysms. Moreover, the US has a low sensitivity for small aneurysms because identification may be compromised by overlying gas and obesity $^{10}$. Spectral Doppler can aid in differentiating vascular from other types of masses and color Doppler shows arterial or turbulent flow in the lesion suggestive of it being a mass of vascular origin ${ }^{11}$.

The HAA can be diagnosed by contrast enhanced CT scan, dynamic CT scan, and CT angiography. The CT angiography is useful for detecting small aneurysms and assessing anatomical details, and is being used instead of angiography. The technique can confirm the diagnosis of HAA, delineates the feeding vessels, depicts collateral blood flow, reveals any other aneurysms and shows anatomic variations of the vessels ${ }^{12}$. However, the need for intravenous contrast limits its use in patients with renal insufficiency or iodine contrast allergy.

Other noninvasive technique for the diagnosis and display of visceral artery aneurysms is tree-dimensional contrast-enhanced MRI angiography, and is being used instead of angiography. Three-dimensional MRI is a fast, accurate and noninvasive technique for the diagnosis and display of visceral artery aneurysms, and attains a better representation of the arterial anatomy and variations and guide selection of an appropriate treatment ${ }^{7,13}$. Since the improvement of MRI technology, three-dimensional dynamic contrast-enhanced MRI angiography may be the optimal vascular imaging method for preoperative evaluation of HAA. Three-dimensional dynamic contrast-enhanced MRI angiography study was performed in our patient revealing in hepatic artery common. 
The selective angiography is the most valuable investigation modality for diagnosis of HAA which has a sensitivity of $100 \%^{14}$. The initial diagnosis of an HAA was made on US scan in this instance and it was confirmed and treated angiographically with superselective coil embolization.

HAA can be treated surgically and surgical ligation of the hepatic artery has been advocated, because the risk of hepatic necrosis has been proven to be small ${ }^{15}$. However, surgical intervention in a patient with high risk operative and postoperative complication other methods for treatment should be considered. Transcatheter coil embolization using the isolation technique is an effective alternative treatment in patients with HAA, being particularly useful in patients whose aneurysms present surgical difficulties ${ }^{16}$.

\section{Conclusion}

In our patient, the clinical result of coil embolization was considered absolutely successful. We believe that in this instance the HAA was developed after the vascular injury during cholecystectomy performed in the past. So, early diagnosis is essential because the natural tendency of the lesion is to rupture into peritoneal cavity or surrounding organs. Endovascular embolization of HAA in selected cases can be considered as a first-line treatment because it is a minimally invasive technique with a low rate of morbidity.

\section{References}

1. Guida PM, Moore SW. Aneurysm of the hepatic artery. Report of five cases with a brief review of previously reported cases. Surgery. 1966;60(2):299-310. PMid:5296691.

2. Tarazov PG, Ryzhkov VK, Polysalov VN, Prozorovskij KV, Polykarpov AA. Extraorganic hepatic artery aneurysm: failure of transcatheter embolization. HPB Surgery. 1998;11(1):55-60. PMid:9830583.

3. Horton KM, Smith C, Fishman EK. MDCT and 3D CT angiography of splanchnic artery aneurysms. AJR Am J Roentgenol. 2007;189(3):641-7.

4. Erskine JM. Hepatic artery aneurysm.Vasc Surg. 1973;7(2):106-25.

5. O'Driscoll D, Olliff SP, Olliff JF. Hepatic artery aneurysm. Br J Radiol. 1999;72(862):1018-25. PMid:10673957.

6. Dougherty MJ, Gloviczki P, Cherry KJ Jr, Bower TC, Hallet JW, Pairolero PC. Hepatic artery aneurysms: evaluation and current management. Int Angiol. 1993;12(2):178-84. PMid:8371001.
7. Pilleul F, Beuf O. Diagnosis of splanchnic artery aneurysms and pseudoaneurysms, with special reference to contrast enhanced 3D magnetic resonance angiography: a review. Acta Radiol. 2004;45(7):702-8. PMid:15624510. http://dx.doi. org/10.1080/02841850410001358

8. Chandramohan C, Khan AN, Fitzgerald S, Sherlock D, Tam E. Sonographic diagnosis and follow-up of idiopathic hepatic artery aneurysm, an unusual cause of obstructive jaundice. J Clin Ultrasound. 2001;29(8):466-71. PMid:11745854.

9. White $\mathrm{WH}$. Cases of jaundice due to aneurysm of the hepatic artery and to movable kidney. Br Med J. 1892;1(1622):223-4. PMid:20753528. http://dx.doi.org/10.1136/bmj.1.1622.223

10. Pasha SF, Gloviczki P, Stanson AW, Kamath PS. Splanchnic artery aneurysms. Mayo Clin Proc. 2007;82(4):472-9. PMid:17418076.

11. Bachar GN, Belenky A, Lubovsky L, Neuman-Levine M. Sonographic diagnosis of a giant aneurysm of the common hepatic artery. J Clin Ultrasound. 2002; 30(5):300-2. PMid:12116110. http://dx.doi. org/10.1002/jcu. 10077

12. Shanley C), Shah NL, Messina LM. Common splanchnic artery aneurysms: splenic, hepatic, and celiac. Ann Vasc Surg. 1996;10(3):315-22. PMid:8793003. http://dx.doi.org/10.1007/ BF02001900

13. Liu Q, Lu JP, Wang F, Wang L, Tian JM. 3D Contrast-enhanced MR angiography of aortic dissection: a pictorial essay. Radiographics. 2007;27(5):1311-21. PMid:17848693.

14. Lumsden AB, Mattar SG, Allen RC, Bacha EA. Hepatic artery aneurysms: the management of 22 patients. J Surg Res. 1996;60(2):345-50. PMid:8598666.

15. Bengmark $\mathrm{S}$, Rosengren $\mathrm{K}$. Angiographic study of the collateral circulation to the liver after ligation of the hepatic artery in man. Am J Surg. 1970;119(6):620-4. http://dx.doi. org/10.1016/0002-9610(70)90228-X

16. Ikeda $O$, Nakasone $Y$, Tamura $Y$, Yamashita $Y$. Endovascular management of visceral artery pseudoaneurysms: transcatheter coil embolization using the isolation technique. Cardiovasc Intervent Radiol. 2010;33(6):1128-34. PMid:20857110. http:// dx.doi.org/10.1007/s00270-010-9973-0

Correspondence
Dr. Luis Jesuíno de Oliveira Andrade
Rua Nações Unidas, 511 - Centro
CEP 45600-673 - Itabuna (BA), Brazil
E-mail: luis_jesuino@yahoo.com.br
Authors' contributions
Conception and design: LOA; ACBS; LSF; LSF; JRS.
Analysis and interpretation: LOA; ACBS; LSF; LSF; JRS.
Data collection: LJOA; JRS.
Writing the article: LJOA; LSF; LSF.
Critical revision of the article: LJOA; ACBS; JRS.
Final approval of the article*: LOA; ACBS; LSF; LSF; JRS.
Statisticalanalysis: Não há dados para análise estatística
Overall responsibility: LJOA; JRS.
*All authors have read and approved the final version submitted at J Vasc Bras.

